\section{Commentary: Protecting the conduction system during transcatheter aortic valve replacement - the higher the better}

\author{
Kendra J. Grubb, MD, MHA, and \\ Gaetano Paone, MD, MHSA
}

As transcatheter treatment of severe symptomatic aortic stenosis has evolved, so too has the scrutiny placed on implanters for the "perfect result." Once a procedure with high complication rates, transcatheter aortic valve replacement (TAVR) is now considered "safer than surgery." Conduction disturbances (CDs), new left bundle branch block, or need for permanent pacemaker implantation, are now the most common complications and are associated with worse outcomes. ${ }^{3}$ For TAVR to truly outperform surgical aortic valve replacement, the occurrence of CDs must be significantly reduced, particularly with self-expanding valve platforms.

In this issue of the Journal, Chen and colleagues present an analysis of the membranous septum (MS) length to optimize the depth of TAVR implant with selfexpanding CoreValve and EvolutR devices. ${ }^{4}$ Building on previous work, they compared the MS length in the coronal view with the infra-annular MS length from the stretched vessel image. ${ }^{5,6}$ An implant depth (ID) of $3.7 \mathrm{~mm}$, coronal MS length of $4.8 \mathrm{~mm}$, and coronal $\triangle \mathrm{MSID}$ of $3.2 \mathrm{~mm}$ were identified as optimal cutoff

From the Division of Cardiothoracic Surgery, Structural Heart and Valve Center, Emory University School of Medicine, Atlanta, Ga.

Disclosures: Dr Paone is a consultant and proctor for Edwards Lifesciences and owns equity in Medtronic plc. Dr Grubb is a consultant and proctor for Medtronic plc.

The Journal policy requires editors and reviewers to disclose conflicts of interest and to decline handling or reviewing manuscripts for which they may have a conflict of interest. The editors and reviewers of this article have no conflicts of interest.

Received for publication Aug 10, 2020; revisions received Aug 10, 2020; accepted for publication Aug 11, 2020; available ahead of print Aug 14, 2020.

Address for reprints: Gaetano Paone, MD, MHSA, Division of Cardiothoracic Surgery, Structural Heart and Valve Center, Emory University Midtown Hospital, 550 Peachtree St, NE, Davis-Fischer Bldg, 4th floor, Atlanta, GA 30308

(E-mail: gaetano.paone@emory.edu).

J Thorac Cardiovasc Surg 2022;164:52-3

$0022-5223 / \$ 36.00$

Copyright (c) 2020 by The American Association for Thoracic Surgery

https://doi.org/10.1016/j.jtcvs.2020.08.023

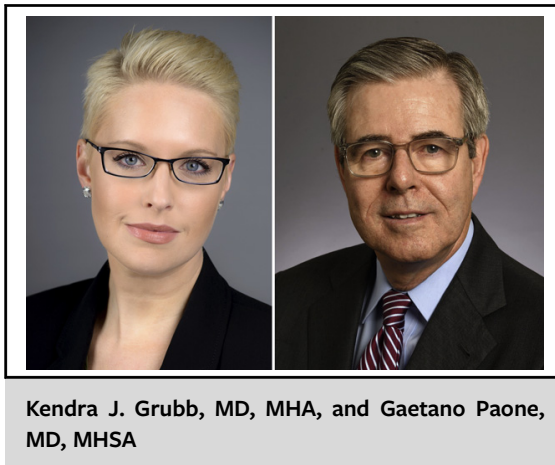

CENTRAL MESSAGE

Reducing conduction disturbances after TAVR with selfexpanding valves ultimately depends upon understanding the position of the membranous septum and the need for a higher depth of implantation.

points for prediction of CDs, with coronal $\triangle$ MSID or infra-annular $\triangle$ MSID the only modifiable predictors. In $12.8 \%$ of the cohort, there was no infra-annular portion of MS at all, a circumstance in which the MS would presumably be completely covered with high risk for developing a CD. Since no patient with MS length greater than $3.2 \mathrm{~mm}$, including those with no infraannular portion, required a pacemaker, the authors conclude “... pre-procedural assessment of MS length should be routinely adopted to determine the optimal ID to mitigate individual patient susceptibility to CDs after TAVR with self-expanding valves." ${ }^{4}$ However, it must be noted that these findings were not used to guide the implants but instead were assessed retrospectively and, therefore, cannot explain the enviable $3.1 \%$ permanent pacemaker implantation and $16.4 \%$ left bundle branch block rates reported.

A detailed implantation technique, initiated with the first CoreValve deployment in 2013 and further modified with EvolutR, is described and presumed responsible for their outstanding results. The authors targeted an optimal ID of $<5 \mathrm{~mm}$ and achieved a median ID $4.5 \mathrm{~mm}$ (interquartile range 2.5 to $6.0 \mathrm{~mm}$ ), a depth relatively shallow compared with best practices at that time. Final positioning was further optimized by recapturing and repositioning as needed and limited postdilatation. The 
distance between the inflow edge of the TAVR frame and the aortic annulus at the noncoronary cusp defined the implant depth, which allowed for better appreciation of the position of the MS with more control of the depth at the non-right commissure.

However measured, patients with shorter MS length and ultimately smaller remaining presumably uncovered portion of the MS (septum length minus implantation depth) were found to be at greater risk for CDs. Yet, the methods used to obtain these more-sophisticated measurements seemingly mattered not nearly as much as the final depth of implantation in successfully mitigating the high rates of $\mathrm{CD}$ often seen with self-expanding valves. The key message then from this elegant work by Chen and colleagues seems simply to be to land the valve as high as safely possible.

\section{References}

1. Popma JJ, Deeb GM, Yakubov SJ, Mumtaz M, Gada H, O’Hair D, et al. Transcath eter aortic-valve replacement with a self-expanding valve in low-risk patients. $N$ Engl J Med. 2019;380:1706-15.

2. Mack MJ, Leon MB, Thourani VH, Makkar R, Kodali SK, Russo M, et al. Transcatheter aortic-valve replacement with a balloon-expandable valve in low-risk patients. N Engl J Med. 2019;380:1695-705.

3. Faroux L, Chen S, Muntané-Carol G, Regueiro A, Philippon F, Sondergaard L, et al Clinical impact of conduction disturbances in transcatheter aortic valve replacement recipients: a systemic review and meta-analysis. Eur Heart J. 2020;41:2771-81.

4. Chen Y-H, Chang H-H, Liao T-W, Leu H-B, Chen I-M, Chen P-L, et al. Membranous septum length predicts conduction disturbances following transcatheter aortic valve replacement. J Thorac Cardiovasc Surg. 2022;164:42-51.e2.

5. Hamdan A, Guetta V, Klempfner R, Konen E, Raanani E, Glikson M, et al. Inverse relationship between membranous septal length and the risk of atrioventricular block in patients undergoing transcatheter aortic valve implant. JACC Cardiovasc Interv. 2015;8:1218-28

6. Jilaihawi H, Zhao Z, Du R, Staniloae C, Saric M, Neuburger PJ, et al. Minimizing permanent pacemaker following repositionable self-expanding transcatheter aortic valve replacement. JACC Cardiovasc Interv. 2019;12:1796-807.

\section{See Article page 42}

\section{Commentary: Landing high, but not too high, yields fewer pacemakers after transcatheter aortic valve replacement}

\author{
Pradeep K. Yadav, MD, ${ }^{\text {a }}$ Christopher U. Meduri, MD, ${ }^{\text {a }}$ \\ and Vinod H. Thourani, MD ${ }^{\mathrm{b}}$
}

Transcatheter aortic valve replacement (TAVR) is now commercially available for the treatment of severe aortic stenosis for all risk groups. Therefore, it is more important than ever to optimize clinical outcomes, considering the longevity of younger patients receiving TAVR. Conduction abnormalities including permanent pacemaker (PPM) and left bundle

\footnotetext{
From the ${ }^{\mathrm{a} D i v i s i o n}$ of Cardiology, and ${ }^{\mathrm{b}}$ Department of Cardiovascular Surgery, Marcus Heart Valve Center, Piedmont Heart Institute, Atlanta, Ga.

Disclosures: Dr Thourani: Abbott Vascular, Boston Scientific, Edwards Lifesciences, and Gore Vascular. Dr Yadav: Edwards Lifesciences, Abbott Vascular, Shockwave Medical. Dr Meduri: Abbott Vascular, Boston Scientific, Medtronic Corp.

The Journal policy requires editors and reviewers to disclose conflicts of interest and to decline handling or reviewing manuscripts for which they may have a conflict of interest. The editors and reviewers of this article have no conflicts of interest.

Received for publication Aug 16, 2020; revisions received Aug 16, 2020; accepted for publication Aug 17, 2020; available ahead of print Aug 20, 2020.

Address for reprints: Vinod H. Thourani, MD, Department of Cardiovascular Surgery, Piedmont Heart Institute, 95 Collier Rd, Suite 5015, Atlanta, GA 30308 (E-mail: vinod.thourani@piedmont.org).

J Thorac Cardiovasc Surg 2022;164:53-4

$0022-5223 / \$ 36.00$

Copyright (c) 2020 by The American Association for Thoracic Surgery

https://doi.org/10.1016/j.jtcvs.2020.08.045
}

Check for updates

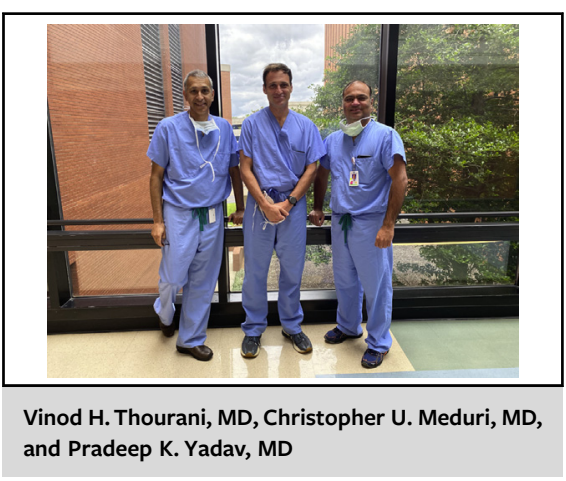

CENTRAL MESSAGE

Implanting the TAVR prosthesis higher (aortic) may reduce the need for permanent pacemaker, and preoperative imaging may guide us in certain patients more vulnerable for complete heart block.

branch block are associated with increased hospitalization for heart failure, lack of improvement in left ventricular ejection fraction, longer intensive care stay, and mortality. ${ }^{1,2}$ The incidence of new PPM comparing the balloon-expandable SAPIEN 3 valve (Edwards Lifesciences, Irvine, Calif) was similar to surgery in the PARTNER 3 randomized trial. ${ }^{3}$ In 